\title{
Foto-diálogos: ensaios sobre o invisível e o inominável em gêneros e sexualidades ${ }^{1}$
}

\author{
Foto-diálogos: ensayos sobre lo invisible y lo inominable en géneros y \\ sexualidades
}
Photo-dialogues: essays on the invisible and the nameless in genres and sexualities

\author{
Dilliany Justino de Lima
}

\begin{abstract}
Resumo
O presente trabalho pretende questionar e refletir sobre a beleza, subjetividade e identidade em corpos cotidianamente violentados pelas estruturas de poder vigentes em nossa sociedade. Seja por questões de classe, raça e/ou gênero, padrões estéticos e de comportamento, a normatização da beleza e das identidades atravessa corpos muitas vezes invisibilizados e subjugados na perspectiva do "outro" dominante. Neste trabalho, o objetivo é materializar e instrumentalizar, por meio da fotografia, a visibilidade e a autonomia na escolha de como esses corpos querem ser vistos. Partindo-se da ideia de formação e construção de identidades e subjetividades sob grande influência do olhar do "outro", a fotografia será utilizada como instrumento de valorização e subversão da ordem heteronormativa, de feminilidades e masculinidades estabelecidas. Numa proposta que poderia ser chamada de foto-diálogo, fotógrafa, fotografados e fotografadas mergulham numa profunda reflexão sobre o quê somos, porquê somos e o quê queremos ser.
\end{abstract}

Palavras-Chave: fotografia; gênero; identidade; sexualidade; subjetividade.

\section{Resumen}

El presente trabajo pretende cuestionar y reflexionar sobre la belleza, subjetividad e identidad en cuerpos cotidianamente violados por las estructuras de poder vigentes en nuestra sociedad. La normativa de la belleza y de las identidades atravesa cuerpos muchas veces invisibilizados y subyugados en la perspectiva del "otro" dominante. En este trabajo, el objetivo es materializar e instrumentalizar, por medio de la fotografía, la visibilidad y la autonomía en la elección de cómo esos cuerpos quieren ser vistos. A partir de la idea de formación y construcción de identidades y subjetividades bajo gran influencia de la mirada del "otro", la fotografía será utilizada como instrumento de valorización y subversión del orden heteronormativo, de feminidades y masculinidades establecidas. En una propuesta que podría ser llamada foto-diálogo, fotógrafa, fotografiados y fotografiadas se sumergen en una profunda reflexión sobre qué somos, por qué somos y qué queremos ser.

Palabras claves: fotografía; género; identidad; sexualidad; subjetividade.

Abstract
The present work aims to question and reflect on beauty, subjectivity and identity in bodies daily violated by the power structures in force in our society. Whether for class, race and / or gender, aesthetic and behavioral standards, the normalization of beauty and identities goes through bodies that are often invisible and subjugated

\footnotetext{
${ }^{1}$ Artigo apresentado no Simpósio Temático (ST 02 - Saberes de desaprendizagens, Artes, Gênero e Sexualidade) durante o II Seminário Latino-Americano de Estudos em Cultura - SEMLACult em Foz do Iguaçu/PR, Brasil, 2018 .

2 Pós-graduanda em Direitos Humanos na América Latina pela Universidade Federal da Integração LatinoAmericana; pós-graduada em Fotografia - Imagem, Memória e Comunicação; graduada em Comunicação Social - Jornalismo pela Universidade Federal Fluminense; Foz do Iguaçu, Paraná, Brasil; dillianyjustino@ gmail.com.
} 
from the perspective of the dominant "other." In this work, the objective is to materialize and instrumentalize, through photography, visibility and autonomy in the choice of how these bodies want to be seen. Starting from the idea of formation and construction of identities and subjectivities under great influence of the "other" view, photography will be used as an instrument of valorization and subversion of the heteronormative order, established femininities and masculinities. In a proposal that could be called photo-dialogue, photographer and photographed immerse themselves in a deep reflection about what we are, why we are and what we want to be. 


\section{Introdução}

Ao longo dos anos, os Estudos de Gênero vêm apresentando questionamentos e reflexões a respeito das relações de poder, ou poderes, subordinação das mulheres e das múltiplas possibilidades de femininos, além de controle dos corpos. Esses estudos integram o desenvolvimento do pensamento crítico dos papéis de gênero desempenhados e da construção do tornar-se mulher. A esse respeito, Judith Butler aponta que, "como uma prática discursiva contínua, o termo está aberto a intervenções e a re-significações” (BUTLER, 2003, p. 58-59), ou seja, é relativamente aceita a concepção de que não existe apenas 'uma' mulher, tampouco 'um' feminino, mas que estas duas categorias são atravessadas por uma complexa rede, que inclui questões étnico-raciais, de classe, identidade de gênero, orientações sexuais, historicidade cultural; que fazem este corpo, político e social, criando vários sentidos do que é ser mulher. Essa rede complexa fica ainda mais evidente se entendida numa perspectiva de interseccionalidade, que visibiliza a amplitude de violências e opressões sofridas por determinados corpos:

\footnotetext{
A interseccionalidade é uma conceituação do problema que busca capturar as consequências estruturais e dinâmicas da interação entre dois ou mais eixos da subordinação. Ela trata especificamente da forma pela qual o racismo, o patriarcalismo, a opressão de classe e outros sistemas discriminatórios criam desigualdades básicas que estruturam as posições relativas de mulheres, raças, etnias, classes e outras. (CRENSHAW, 2002: 177).
}

Para além disso, é importante lembrar que "o corpo está sempre sitiado, sofrendo a destruição pelos próprios termos da história. E a história é a criação de valores e significados por uma prática significante que exige a sujeição do corpo" (BUTLER, 2003, p. 225). Na perspectiva do "outro" dominante, a normatização da beleza e das identidades atravessa corpos muitas vezes invisibilizados e subjugados, produzindo discursos que colocam determinadas vidas em vulnerabilidade.

Neste sentido, para além da importância da coletividade dos movimentos feministas e de questionamento dos papéis de gênero, por exemplo, quando se pensa em subversão da ordem, é, possivelmente, no campo do indivíduo que aparecerão as resistências que demonstram a pluralidade de sentidos, corpos, sexualidades e gêneros fora da norma e potenciais sujeitos de outras narrativas que sendo: 
[...] Possíveis, necessárias, improváveis, espontâneas, selvagens, solitárias, planejadas, arrastadas, violentas, irreconciliáveis, prontas ao compromisso, interessadas ou fadadas ao sacrifício; por definição, não podem existir a não ser no campo estratégico das relações de poder. Mas isso não quer dizer que sejam subproduto das mesmas, [...] Também são, portanto, distribuídas de modo irregular: os pontos, os nós, os focos de resistência disseminam-se com mais ou menos densidade no tempo e no espaço, às vezes provocando o levante de grupos ou indivíduos de maneira definitiva, inflamando certos pontos do corpo, certos momentos da vida, certos tipos de comportamento. (FOUCAULT, 1985, p. 91).

Ao se pensar em resistências e em subversão dos padrões normativos, é importante também levantar outros pontos. Quem vai contra a ordem dominante constantemente se depara com questões negativas, de rejeição ou até mesmo violência. Butler (2003) fala de repúdio aos corpos em consequência de seu sexo, sexualidade e/ou cor, repúdio esse que consolida identidades predominantes e hegemônicas. É a exclusão e dominação do Outro agindo na regulação e controle sociais.

\section{Objetivos}

O presente trabalho pretende provocar questionamentos e reflexões sobre beleza, gênero, subjetividade e identidade em corpos cotidianamente violentados pelas estruturas de poder vigentes em nossa sociedade contemporânea.

Pensar beleza, gênero e categorias de femininos e masculinos também é pensar representação política, linguística, cultural e de imagem. É pensar representação e representatividade de sentidos e identidades, e, sobretudo, as construções do que é representado, do que vale a pena ser representado, do que é reconhecido enquanto sujeito nessa representação, e do que é entendido como belo. Deve-se considerar aqui a relevância da repetição e do que pode se chamar de confronto, ou embate cultural no reconhecimento da normalidade.

A sutileza do embate cultural requer um olhar igualmente sutil. Há que perceber os modos como se constrói e se reconstrói a posição da normalidade e a posição da diferença, porque, afinal, é disso que se trata. Em outras palavras, é preciso saber quem é reconhecido como sujeito normal, adequado, sadio e quem se diferencia desse sujeito. As noções de norma e de diferença tornaram-se particularmente relevantes na contemporaneidade. É preciso refletir sobre seus possíveis significados. (LOURO, 2008, v. 19, n. 2, p. 21-22)

Entre os objetivos deste trabalho está a entrada neste embate no sentido de buscar representações possíveis de belezas para além dos estereótipos construídos e reforçados diariamente, para além da padronização dos corpos. Ademais, a ideia é trabalhar essas 
representações baseadas na autonomia dos corpos de criar a sua própria representação, fora do papel de objetos e dentro de um papel protagonista de construção coletiva.

\title{
3. . Metodologia
}

Enquanto Butler pergunta: "que tipo de repetição subversiva poderia questionar a própria prática reguladora da identidade?" (BUTLER, 2003, p. 57) e “o que constituiria a possibilidade de inversão, subversão ou deslocamentos efetivos nos termos de uma identidade construída?" (BUTLER, 2003, p. 58), Berenice Bento fala sobre a capacidade dos sujeitos construírem novos sentidos para os femininos e masculinos e a "capacidade performática" da linguagem na produção de feminilidades e masculinidades, "a verdade dos gêneros não está no corpo, mas nas possibilidades múltiplas de construir novos significados para os gêneros", (BENTO, 2012, p. 47). E, levando-se em consideração que nos é ensinado a ser mulher (ou homem),

\begin{abstract}
Aprendemos a viver o gênero e a sexualidade na cultura, através dos discursos repetidos da mídia, da igreja, da ciência e das leis e também, contemporaneamente, através dos discursos dos movimentos sociais e dos múltiplos dispositivos tecnológicos. As muitas formas de experimentar prazeres e desejos, de dar e de receber afeto, de amar e de ser amada/o são ensaiadas e ensinadas na cultura, são diferentes de uma cultura para outra, de uma época ou de uma geração para outra. E hoje, mais do que nunca, essas formas são múltiplas. As possibilidades de viver os gêneros e as sexualidades ampliaram-se. As certezas acabaram. Tudo isso pode ser fascinante, rico e também desestabilizador. Mas não há como escapar a esse desafio. (LOURO, 2008, v. 19, n. 2, p. 22-23)
\end{abstract}

Entre as possibilidades de construção de novos sentidos para os femininos e a própria elucidação da pluralidade dos femininos já existentes, e do que se considera belo, a arte pode ser um instrumento. No presente trabalho, a proposta é utilizar a fotografia enquanto ferramenta de subversão dos sentidos reguladores de uma identidade e beleza feminina.

Por meio da fotografia, o objetivo é materializar e instrumentalizar a visibilidade e a autonomia na escolha de como esses corpos fotografados querem ser vistos. Partindo-se da ideia de formação e construção de identidades e subjetividades sob grande influência do olhar do "outro", a fotografia aqui é utilizada como instrumento de valorização e subversão da ordem heteronormativa, de belezas, feminilidades e masculinidades estabelecidas. Numa proposta que poderia ser chamada de foto-diálogo, pretende-se uma profunda reflexão sobre o quê somos, porquê somos e o quê queremos ser.

Se "diante da objetiva, sou ao mesmo tempo: aquele que eu me julgo, aquele que eu gostaria que me julgassem, aquele que o fotógrafo me julga e aquele de que ele se serve para 
exibir sua arte" (BARTHES, 1984, p. 23), na fotografia associada ao diálogo e a um processo coletivo pretende-se romper os próprios pré-julgamentos na busca por um encontro com si mesmo.

A relação fotógrafo-fotografado, marcada por uma estrutura de poder de quem possui a câmera em mãos, é repensada numa nova perspectiva, que exige um novo processo fotográfico, que traga para perto e para dentro quem antes tinha um papel simplificado de objeto.

Para Rouillé (2009), o mais importante não é que os fotógrafos representem o mundo em toda sua diversidade, mais do que isso, o importante é a transformação que se pode causar. Uma das possibilidades que o autor coloca é um processo dialógico, onde quem é fotografado tem papel ativo, e "ao colocar-se o mais próximo possível dos indivíduos singulares, transformando-os em sujeitos, o procedimento adotado mescla a produção de imagens e a resistência aos efeitos da precariedade" (ROUILLÉ, 2009, p. 179), conceito esse que conversa com a precariedade e a vulnerabilidade da vida humana tratadas por Butler (2006).

\section{Resultados esperados}

O que se propõe aqui não se assemelha à ideia do processo fotográfico enquanto busca do real e da verdade, mas uma construção conjunta de olhares e representatividades, um afrontamento à própria precariedade, com base no diálogo, que pretende resultar em algo bem próximo de um autorretrato. O Outro aqui "é aquele que subverte as normas, que desafia os padrões, que faz vacilar o poder, que perturba os valores dominantes, os princípios das maiorias. O Outro é menor. Aquele que desafia o maior" (ROUILLÉ, 2009, p. 181).

$\mathrm{Na}$ busca pelo que se quer capturar e representar, a proposta dialógica é coletiva e interdisciplinar, e vai contra as abordagens onde o Outro é apenas um objeto, onde a fotografia, o enquadramento, impera sobre as pessoas. Aqui, a ideia é que as pessoas fotografadas importem mais que a própria fotografia, e o que se produz são "imagens com", e não "imagens de" ou "imagens para".

Considerando-se que nenhum corpo está livre das influências dos discursos e que "o ato da linguagem não é uma representação da realidade, mas uma interpretação construtora de significados" (BENTO, 2012, p. 36), pretende-se utilizar a fotografia enquanto apropriação de uma linguagem para a representação de si mesmo, numa ruptura das estruturas de poder ainda presentes na escolha do que é visível e relevante. Vale ressaltar que o que se pretende não é 
RELACult - Revista Latino-Americana de Estudos em Cultura e Sociedade

Revista Latinoamericana de Estudios en Cultura y Sociedad | Latin American Journal of Studies in Culture and Society V. 05, ed. especial, mai., 2019, artigo $\mathrm{n}^{\circ} 1605$ | claec.org/relacult | e-ISSN: 2525-7870

tornar o Outro visível, mas construir o discurso e a narrativa da representação de forma que a visibilidade seja autônoma e coletiva. 


\section{Ensaio fotográfico}

Para o presente trabalho foi realizado um ensaio fotográfico baseado na metodologia proposta de foto-diálogo. Uma mulher que se dispôs a ser fotografada a partir de um intenso diálogo sobre suas experiências e vivências enquanto feminilidades que rompem, de maneiras diferentes e singulares, com normatividades do que é considerado ser mulher pelo senso comum. Seja por questões estéticas e/ou de sexualidades não-normativas, é uma mulher que levou alguns anos de sua vida para compreender a própria identidade e compartilhou suas reflexões comigo ao construirmos imagens.

Para colocar esta proposta em prática é necessário encontrar pessoas dispostas a darem esse mergulho, o que pode não ser muito fácil. Esse convite a possíveis participantes pode ser um processo demorado, muitas conversas, trocas, construções conceituais, para enfim fazer o ensaio fotográfico em si. E não é apenas isso que precisa ser levado em consideração, pois sendo uma proposta horizontal e coletiva, a pessoa fotografada participa de todas as etapas, e todas as fotos apresentadas ao final são resultado desse diálogo. Se a ideia é que as pessoas realmente se vejam nas fotos, a escolha delas também é um momento muito relevante.

Tainara Protásio é uma amiga e por muitos motivos comecei a conversar com ela sobre este trabalho. Ela gostou da ideia e o dia do ensaio foi precedido de muita conversa e troca. Tainara se encontrava em um momento de muitas mudanças, de repensar muitas coisas, de vivências novas e intensas. Ela leu o que já havia escrito sobre a proposta antes de fazermos as fotos. Durante o ensaio ela ficou totalmente livre e minha direção foi somente no sentido de facilitar os resultados que ela esperava. Foi um ensaio muito intenso e o relato dela sobre o que foi viver esta experiência pode se resumir nas seguintes falas:

"nunca ninguém me fotografou desse jeito"

"e estava vestida o tempo todo, mas me sentindo totalmente nua"

"eu sempre estou sorrindo pra todo mundo, nesse momento eu percebo que não preciso ser assim"

"acho que você conseguiu captar muito o que sinto nesse momento"

Cada processo de foto-diálogo/diálogo-foto requer tempo. E foi exatamente isso o que aconteceu neste trabalho, muito tempo, muitas trocas e muitas conversas para chegar aos resultados aqui apresentados. 
RELACult - Revista Latino-Americana de Estudos em Cultura e Sociedade

Revista Latinoamericana de Estudios en Cultura y Sociedad | Latin American Journal of Studies in Culture and Society V. 05, ed. especial, mai., 2019, artigo $\mathrm{n}^{\circ} 1605$ | claec.org/relacult |e-ISSN: 2525-7870

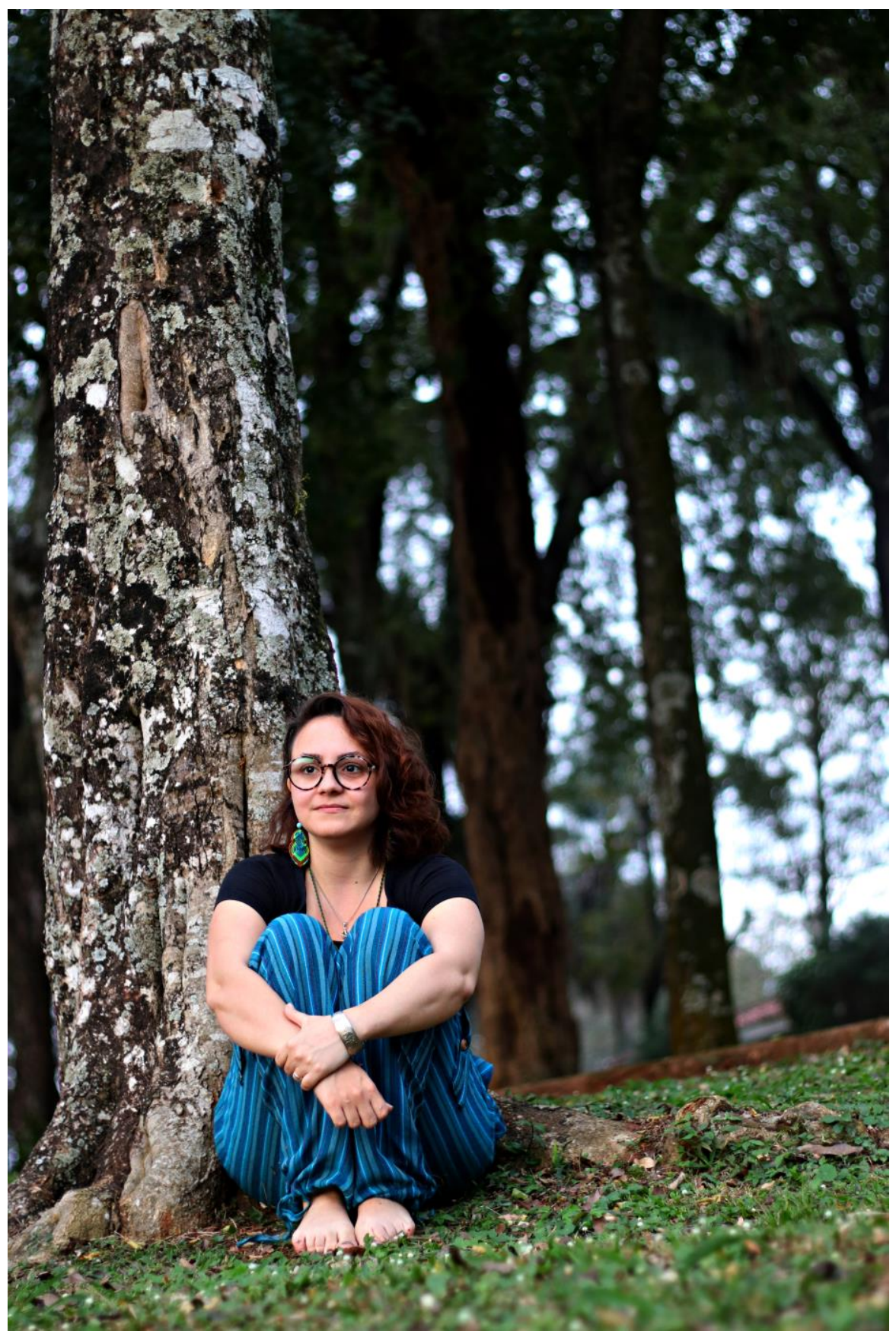

Fotografia 1 - Tainara 
RELACult - Revista Latino-Americana de Estudos em Cultura e Sociedade

Revista Latinoamericana de Estudios en Cultura y Sociedad | Latin American Journal of Studies in Culture and Society V. 05, ed. especial, mai., 2019, artigo no 1605 | claec.org/relacult | e-ISSN: 2525-7870

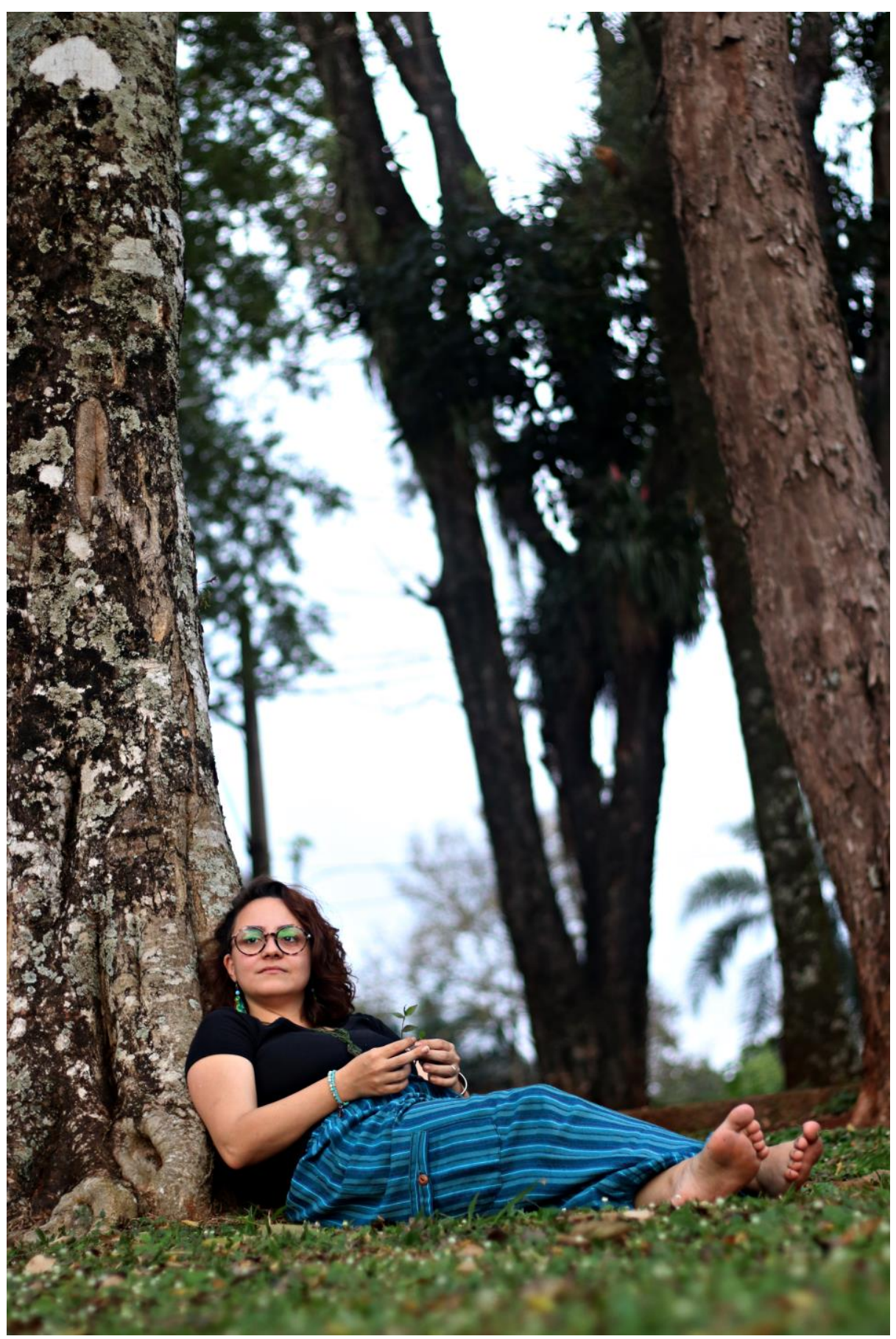

Fotografia 2 - Tainara 
RELACult - Revista Latino-Americana de Estudos em Cultura e Sociedade

Revista Latinoamericana de Estudios en Cultura y Sociedad | Latin American Journal of Studies in Culture and Society V. 05, ed. especial, mai., 2019, artigo $\mathrm{n}^{\circ} 1605$ | claec.org/relacult | e-ISSN: 2525-7870

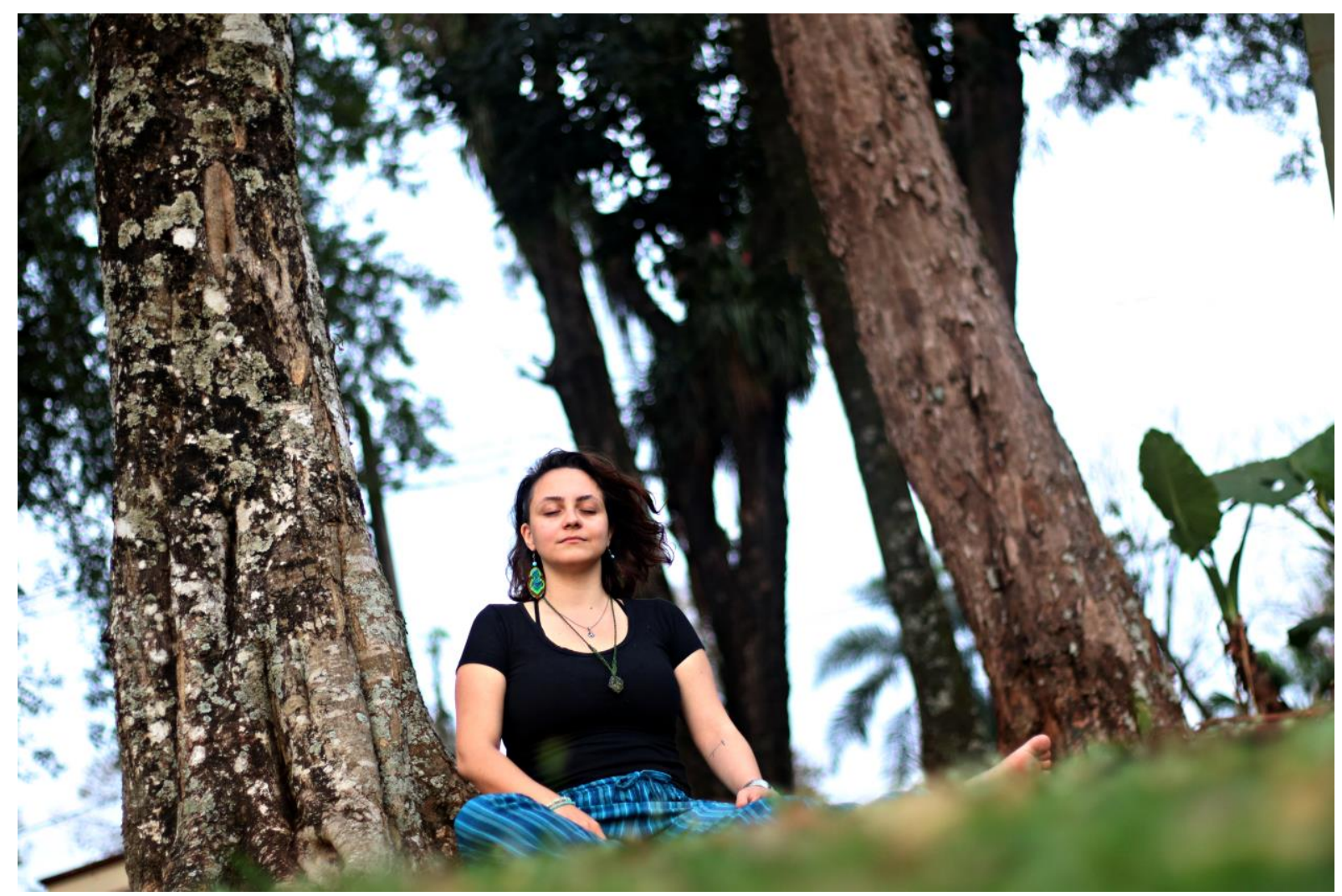

Fotografia 3 - Tainara 
RELACult - Revista Latino-Americana de Estudos em Cultura e Sociedade

Revista Latinoamericana de Estudios en Cultura y Sociedad | Latin American Journal of Studies in Culture and Society V. 05, ed. especial, mai., 2019, artigo $\mathrm{n}^{\circ} 1605$ | claec.org/relacult |e-ISSN: 2525-7870

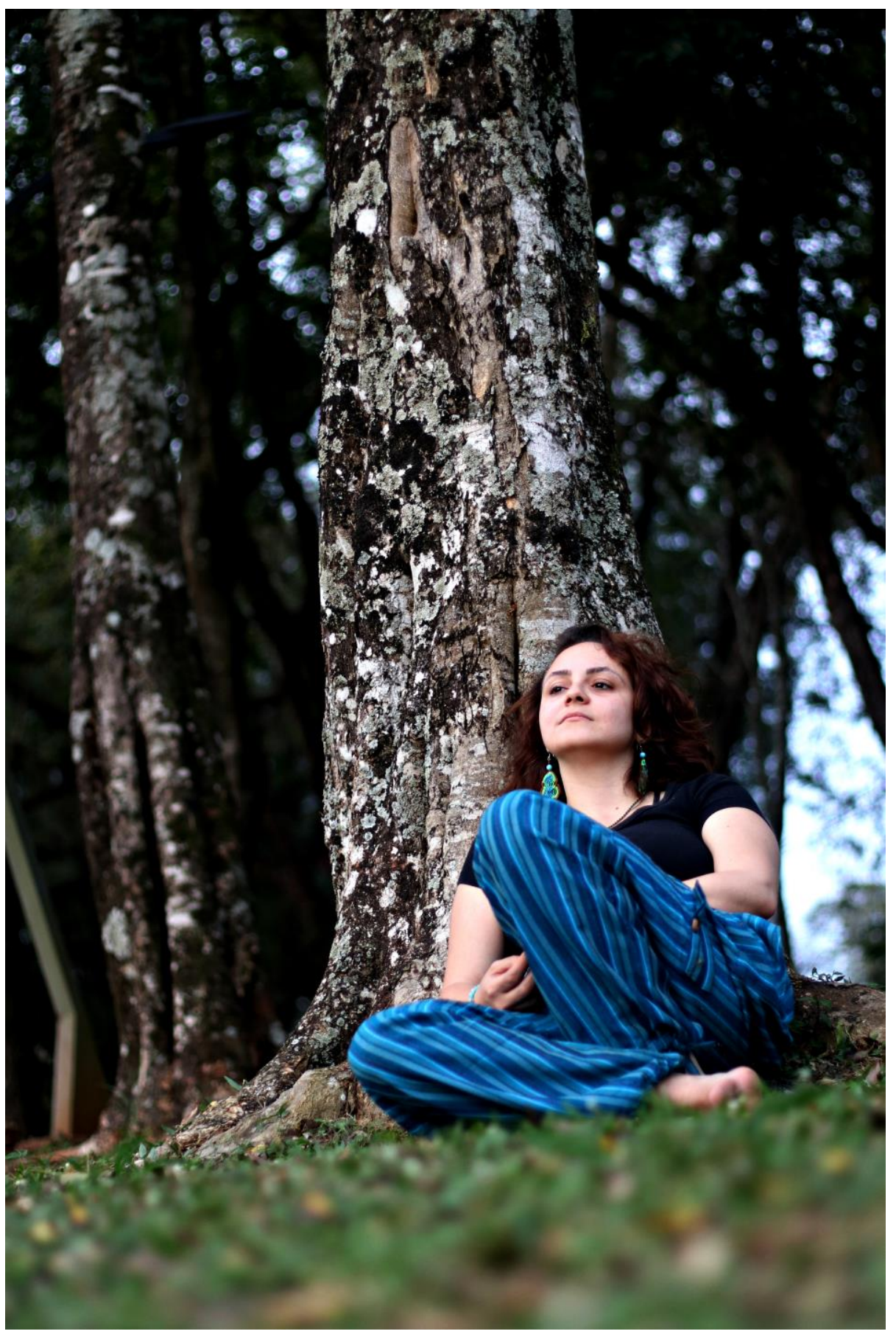

Fotografia 4 - Tainara 
RELACult - Revista Latino-Americana de Estudos em Cultura e Sociedade

Revista Latinoamericana de Estudios en Cultura y Sociedad | Latin American Journal of Studies in Culture and Society V. 05, ed. especial, mai., 2019, artigo $\mathrm{n}^{\circ}$ 1605 | claec.org/relacult |e-ISSN: 2525-7870

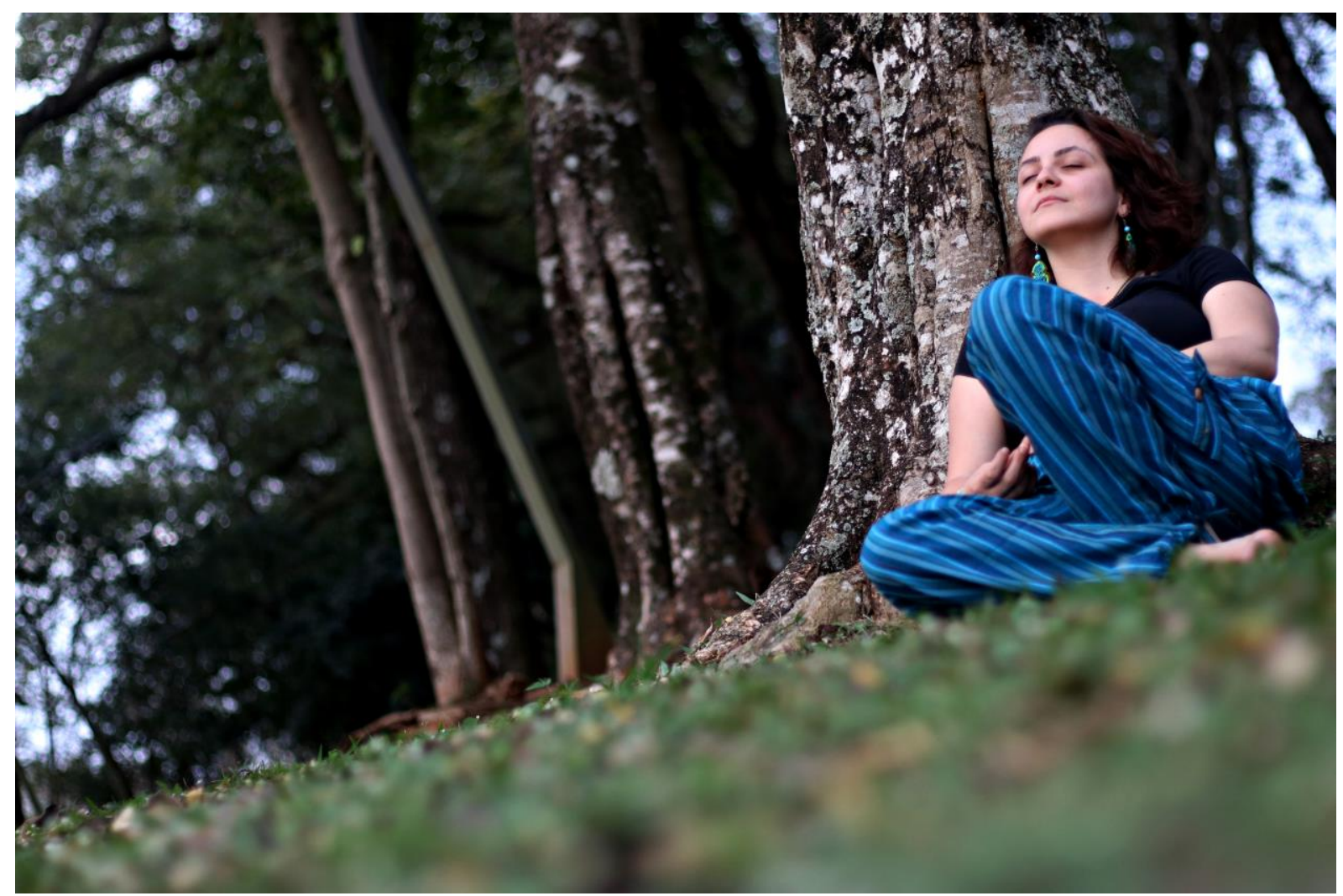

Fotografia 5 - Tainara 
RELACult - Revista Latino-Americana de Estudos em Cultura e Sociedade

Revista Latinoamericana de Estudios en Cultura y Sociedad | Latin American Journal of Studies in Culture and Society V. 05, ed. especial, mai., 2019, artigo $\mathrm{n}^{\circ} 1605$ | claec.org/relacult |e-ISSN: 2525-7870

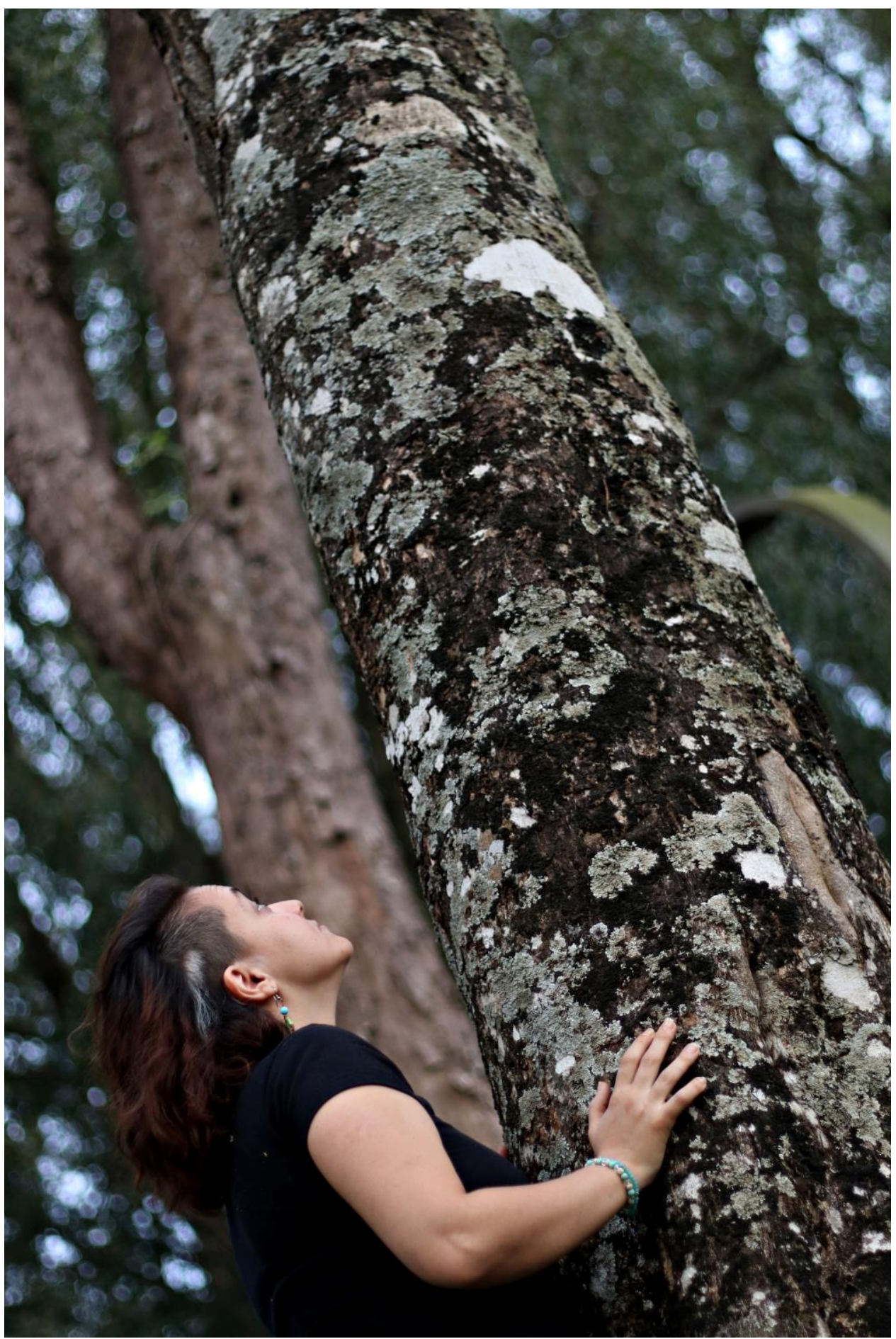

Fotografia 6 - Tainara 
RELACult - Revista Latino-Americana de Estudos em Cultura e Sociedade

Revista Latinoamericana de Estudios en Cultura y Sociedad | Latin American Journal of Studies in Culture and Society V. 05, ed. especial, mai., 2019, artigo $\mathrm{n}^{\circ} 1605$ | claec.org/relacult |e-ISSN: 2525-7870

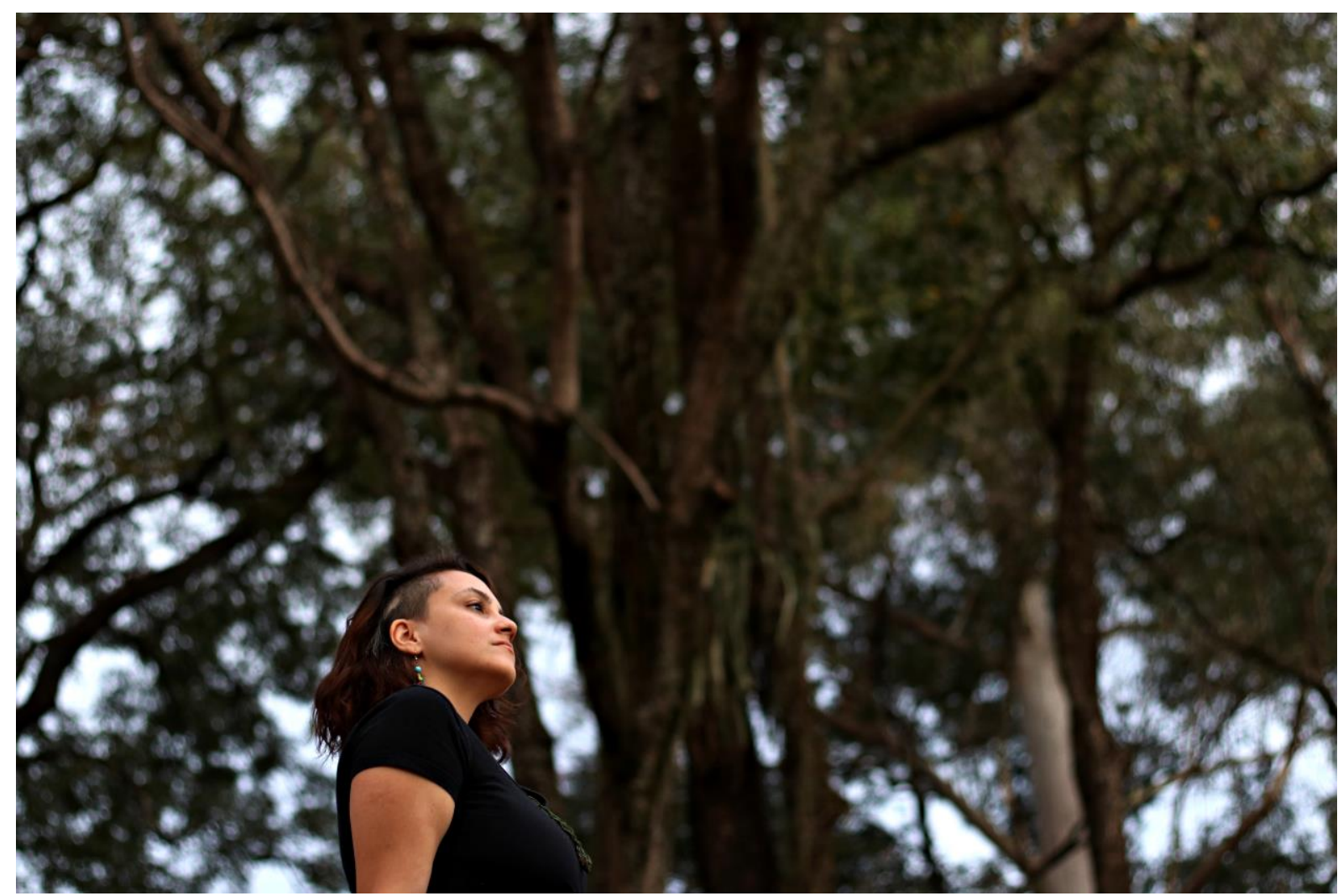

Fotografia 7 - Tainara

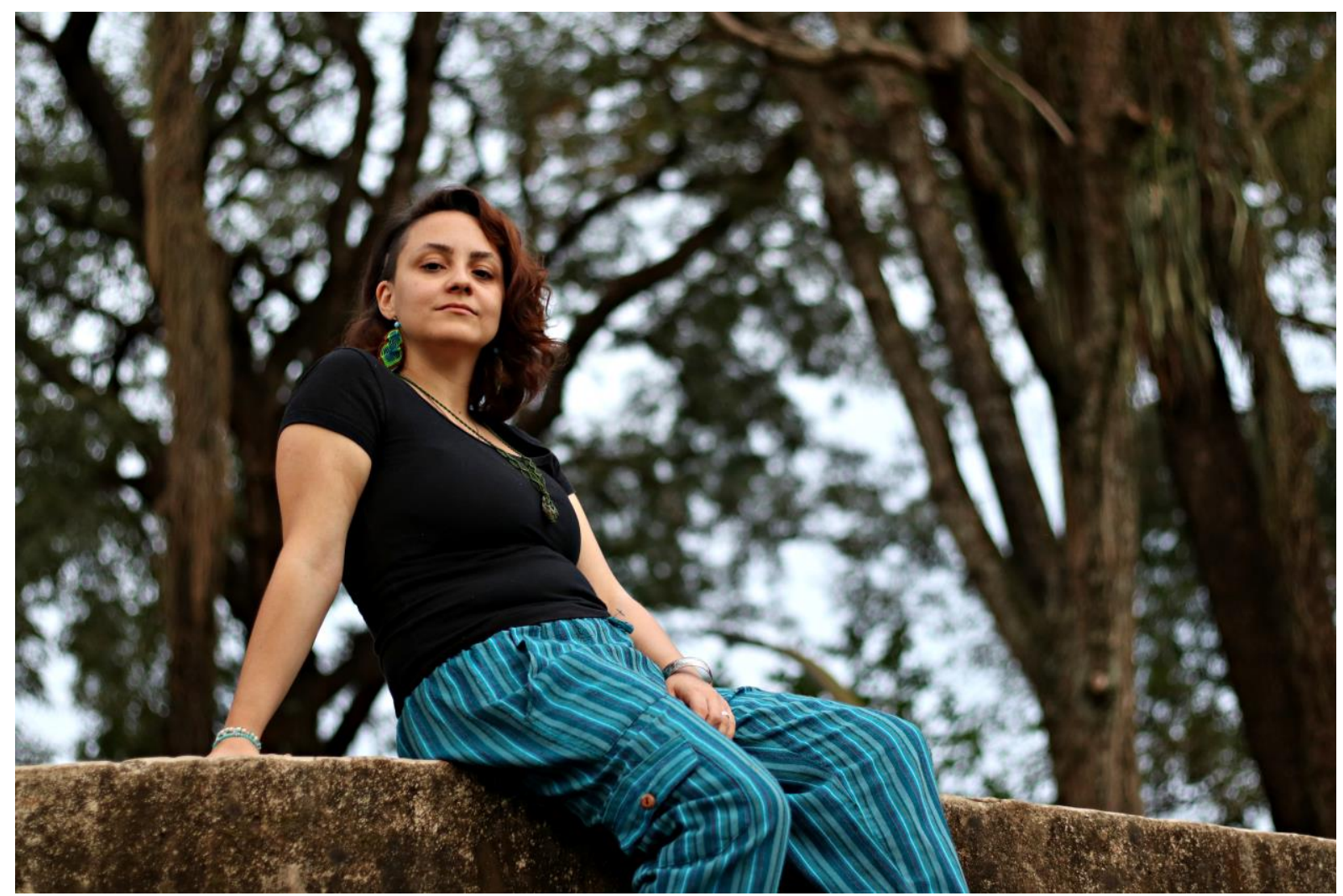

Fotografia 8 - Tainara 
RELACult - Revista Latino-Americana de Estudos em Cultura e Sociedade

Revista Latinoamericana de Estudios en Cultura y Sociedad | Latin American Journal of Studies in Culture and Society V. 05, ed. especial, mai., 2019, artigo no 1605 | claec.org/relacult | e-ISSN: 2525-7870

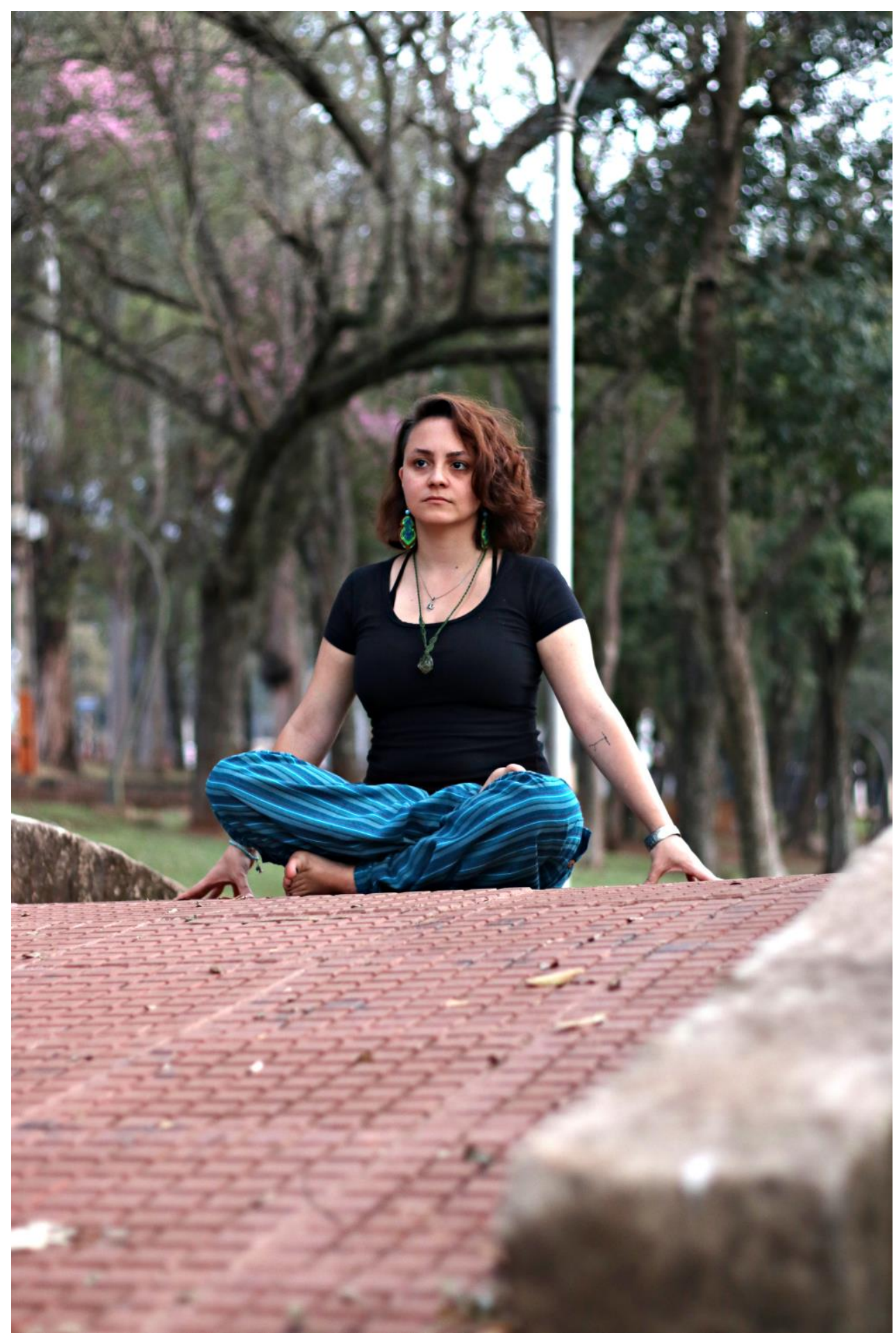

Fotografia 9 - Tainara 
RELACult - Revista Latino-Americana de Estudos em Cultura e Sociedade

Revista Latinoamericana de Estudios en Cultura y Sociedad | Latin American Journal of Studies in Culture and Society V. 05, ed. especial, mai., 2019, artigo $\mathrm{n}^{\circ}$ 1605 | claec.org/relacult | e-ISSN: 2525-7870

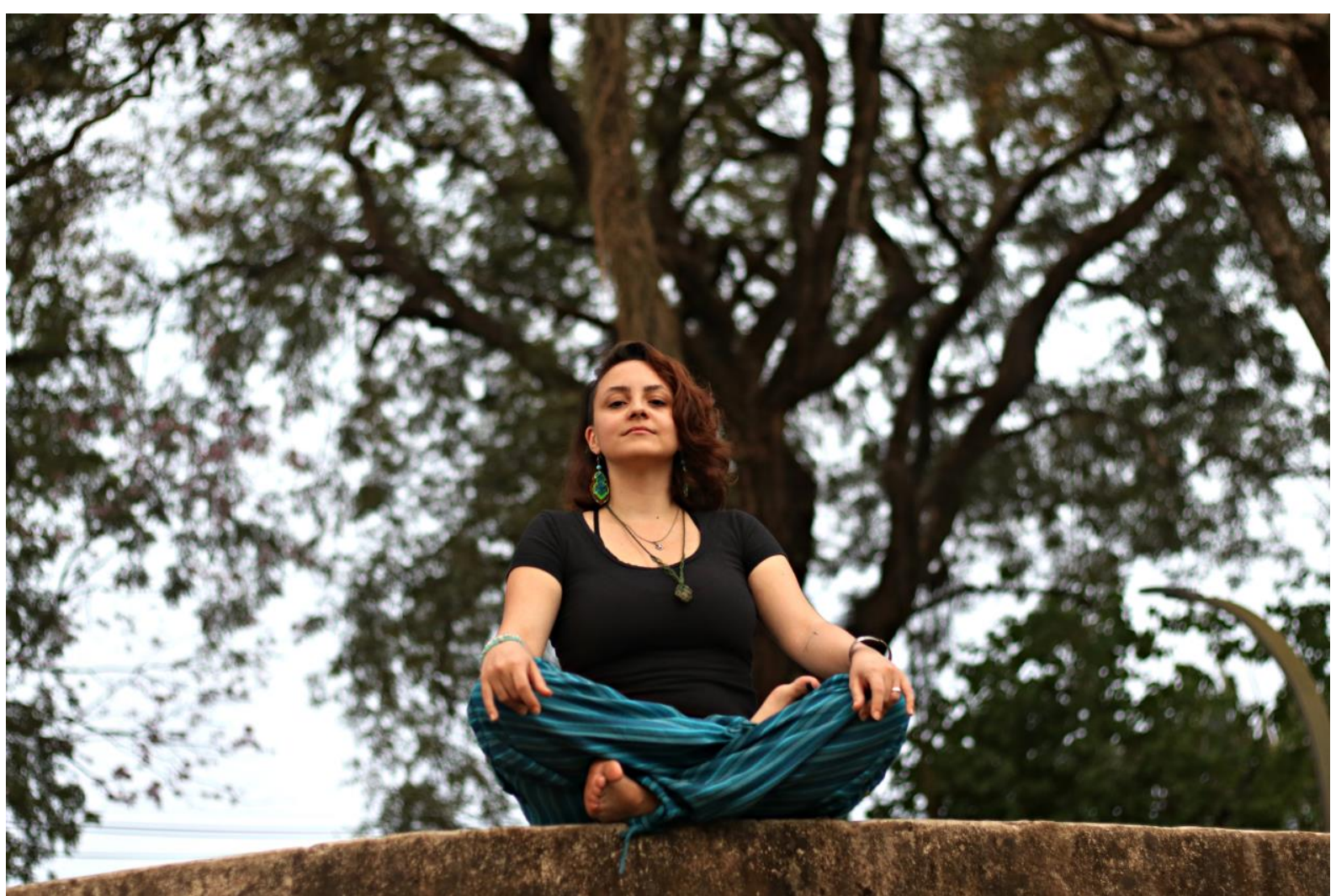

Fotografia 10 - Tainara 


\title{
6. Considerações finais
}

No presente trabalho, subalternizados e invisibilizados são convidados a tomarem como referência suas próprias histórias, vivências, estéticas e corpos, na busca por imagens que revelem como querem se mostrar e como querem ser vistos pelo mundo. Este é um processo que requer tempo e disponibilidade para um mergulho e um pensar sobre si mesmo, além de uma relação de cumplicidade entre os envolvidos que será determinante para os resultados encontrados.

Para que se rompa com a invisibilidade e a não valorização das diversas possibilidades de belezas é importante que os próprios invisibilizados tenham autonomia e protagonismo neste processo e na escolha de como querem se mostrar para o outro e para si mesmo.

Tendo em vista que o que subverte ou tenta subverter a ordem dominante esbarra necessariamente em relações de poder, e poderes, sabe-se que nesse processo é preciso se utilizar da própria norma, ao mesmo tempo que somos usados por ela. Além dos riscos aí implicados, a disputa passa ainda pelo que é digno de reconhecimento e de que forma é reconhecido.

\begin{abstract}
Há uma norma em atuação, invariavelmente social, que condiciona o que será e o que não será um relato reconhecível, exemplificada no fato de que sou usada pela norma precisamente na medida em que a uso. E não é possível fazer nenhum relato de mim mesma que, em certa medida, não se conforme às normas que governam o humanamente reconhecível ou negocie esses termos de alguma maneira, com vários riscos originando-se dessa negociação. (BUTLER, 2015, p. 51)
\end{abstract}

Se não é possível fugir à negociação e se "alguns humanos consideram natural sua condição de humanidade, ao passo que outros batalham para garantir o acesso a ela" (BUTLER, 2015, p. 117), a tentativa é de se basear em um autorreferencimento que não tenha como parâmetro os padrões e as narrativas hegemônicas, mas uma apropriação do próprio "ser" e a possibilidade de contar a própria narrativa, partindo-se de si mesmo.

Mas significa que se me posiciono como se pudesse reconstruir as normas pelas quais se instaura e se sustenta minha condição de sujeito, então recuso a própria desorientação e interrupção da minha narrativa implicadas pela dimensão social dessas normas. (BUTLER, 2015, p. 107)

Os resultados encontrados enquanto imagens representam acúmulos pessoais e coletivos na tentativa de se chegar o mais próximo da representatividade buscada. 


\section{Referências bibliográficas}

BARTHES, Roland. A câmara clara: nota sobre a fotografia. Rio de Janeiro: Nova Fronteira, 1984.

BENTO, Berenice. O que é transexualidade. Brasiliense, 2008.

BUTLER, Judith. Problemas de gênero: feminismo e subversão da identidade. Rio de Janeiro: Editora Civilização Brasileira, 2003.

BUTLER, Judith. Relatar a si mesmo: crítica da violência ética. São Paulo: Autêntica, 2015.

CRENSHAW, Kimberlé. Documento para o encontro de especialistas em aspectos da discriminação racial relativos ao gênero. Estudos feministas, v. 10, n. 1, p. 171, 2002.

FLUSSER, Vilém. Filosofia da caixa preta. Ensaios para uma futura filosofia da fotografia. São Paulo: Annablume, 2011.

FOUCAULT, Michel. História da sexualidade (vols. 1, 2 e 3). Rio de Janeiro: Paz e Terra, 2013.

HALL, Stuart. Da diáspora: Identidades e mediações culturais. Belo Horizonte: Editora UFMG, 2003.

LOURO, Guacira Lopes. Gênero e sexualidade: pedagogias contemporâneas. Pro-posições, v. 19 , n. 2, p. 17-23, 2008.

ROUILLÉ, André. A fotografia: entre documento e arte contemporânea. Senac, 2009.

SONTAG, Susan. Diante da dor dos outros. Editora Companhia das Letras, 2003.

SONTAG, Susan. Sobre fotografia. São Paulo: Companhia das Letras, 2004.

SPIVAK, Gayatri Chakravorty. Pode o Subalterno Falar? Belo Horizonte: Editora UFMG, 2010. 